Supporting Information

\title{
Charge Transfer Through Terthiophene End-Capped Poly(arylene ethynylene)s
}

Alison M. Funston, ${ }^{\dagger}$ Eric E. Silverman, ${ }^{\neq}$John R. Miller* $^{\dagger}$ and Kirk S. Schanze ${ }^{* \neq}$

Chemistry Department, Brookhaven National Laboratory, Upton, NY, 11973 and

Department of Chemistry, University of Florida, PO Box 117200, Gainesville, FL 32611-7200

${ }^{\dagger}$ Brookhaven National Laboratory

* University of Florida

* Authors to whom correspondence should be addressed

For all correspondence:

John R. Miller

Telephone: 631344 4354; Facsimile: 6313445815

e-mail: jrmiller@bnl.gov

Kirk S. Schanze

Telephone: 352392 9133; Facsimilie: 3523922395

e-mail:kschanze@chem.ufl.edu 


\section{Synthetic Procedures}

2,5-diiodo-1,4-dimethoxybenzene. This compound was prepared by a modified literature procedure. ${ }^{1}$ A solution of potassium periodate $(8.0 \mathrm{~g}, 35 \mathrm{mmol})$ in water $(30 \mathrm{~mL})$ was added to a round bottom flask charged with 1,4-dimethoxybenzene $(6.9 \mathrm{~g}, 50.0 \mathrm{mmol})$ and iodine $(12.7 \mathrm{~g}$, $50.0 \mathrm{mmol})$ and acetic acid $(120 \mathrm{~mL})$. The flask was fitted with a condenser, and the solution was heated to a gentle reflux with stirring. After attaining reflux, a solution of sulfuric acid (3.0 $\mathrm{mL}$ in $15 \mathrm{~mL}$ water) was added slowly through the condenser. An exothermic reaction was observed after addition of the first few drops of acid solution, and the heating was suspended temporarily until addition of the sulfuric acid was complete. The reaction was then returned to reflux. After approximately 30 minutes, the brown iodine color of the solution appeared significantly lighter. (Caution: While the solution is refluxing, crystals of iodine sublime into the condenser, and it is necessary to use a long glass rod to push these crystals back into the solution. If the condenser becomes completely clogged with iodine, an explosion may result due to the buildup of gas pressure in the system.) When 1.5 hours had elapsed after the addition of sulfuric acid, heat was removed from the reaction and it was allowed to cool to room temperature. The solution was then treated with a saturated aqueous solution of $\mathrm{Na}_{2} \mathrm{~S}_{2} \mathrm{O}_{4}$ until no iodine color was noticeable. The reaction mixture was diluted with water to double the original volume to induce precipitation of the product as yellow crystals. The solid is collected by vacuum filtration, washed with water, and recrystallized from hot acetone/water giving the desired product as a white, crystalline solid, yield $17.4 \mathrm{~g}(89 \%)$.

2,5-diodo-1,4-dihydroquinone. This compound was prepared by a modified literature

procedure. ${ }^{1}$ A $500 \mathrm{~mL}$ Erlenmeyer flask with a ground-glass top was charged with 2,5-diiodo1,4-dimethoxybenzene $(30.0 \mathrm{~g}, 76.9 \mathrm{mmol})$ and $350 \mathrm{~mL}$ methylene chloride (previously dried over $\mathrm{P}_{2} \mathrm{O}_{5}$ ). The resulting solution was cooled in a bath of ethanol and liquid nitrogen, and fitted with a condenser. Neat $\mathrm{BBr}_{3}(38.5 \mathrm{~g}, 14.5 \mathrm{~mL}, 153.8 \mathrm{mmol})$ was added slowly through the condenser. After the addition was complete, a septum cap was affixed to the top of the 
condenser, and a gentle flow of $\mathrm{N}_{2}$ gas was introduced to the reaction through a needle. The mixture was allowed to warm to room temperature, then heated to reflux and stirred for 48 hours. After this time, small portions of methanol and then water were added to the solution. Methylene chloride was evaporated by rotory evaporation and the residue was diluted with methanol-water $(80: 20)$. A few spatula tips of sodium sulfite $\left(\mathrm{Na}_{2} \mathrm{SO}_{3}\right)$ was then added. The solution was then placed in the freezer overnight, after which fine off-white crystals of product formed and were collected by vacuum filtration, yield $24.9 \mathrm{~g}(89 \%)$.

2,5-bis-(2-ethylhexyloxy)-1,4-diiodobenzene. This compound was prepared by a modification of a literature procedure. ${ }^{1}$ To a solution of 2,5-diiodohydroquinone $(4.24 \mathrm{~g}, 11$ mmol) in methyl ethyl ketone $(80 \mathrm{~mL})$ in an Erlenmeyer flask with a ground-glass top was added potassium carbonate $(15.2 \mathrm{~g}, 110 \mathrm{mmol})$. The system was fitted with a condenser, and a nitrogen inlet and outlet. The mixture was gently heated for 20 min with stirring to dissolve most of the potassium carbonate. Then 1-bromo-2-ethylhexane $(2.5 \mathrm{~mL}, 44 \mathrm{mmol})$ was added via syringe. The system was then heated to reflux for 16 hours. Substantial amounts of salt precipitated over the course of the reaction. After reflux, $1 \mathrm{~g}$ of sodium sulfite $\left(\mathrm{Na}_{2} \mathrm{SO}_{3}\right)$ was added to the mixture, and the solution was then neutralized by slow addition of $1 \mathrm{~N}$ aqueous $\mathrm{HCl}$. The reaction mixture remained under positive nitrogen pressure, with an outlet to allow for the escape of gasses, during the entire process. After neutralization the mixture was further diluted with 100 $\mathrm{mL}$ of warm $\left(40^{\circ} \mathrm{C}\right)$ water, and stirred for one hour. The mixture was then extracted with pentanes $(3 \times 40 \mathrm{~mL})$ and the organic layer was dried over $\mathrm{MgSO}_{4}$ and concentrated to a volume of $10 \mathrm{~mL}$. The concentrated pentane solution was passed through a short (3" length, 2"diameter) column of silica by elution with $200 \mathrm{~mL}$ of pentanes, followed by evaporation of the solvent under reduced pressure afforded the desired product as a clear liquid, yield $4.07 \mathrm{~g}, 63 \% . \quad{ }^{1} \mathrm{H}$ NMR $\left(\mathrm{CDCl}_{3}\right): \delta$ 0.9-1.8 (complex multiplet, 26H), $3.8(\mathrm{t}, 4 \mathrm{H}), 7.1(\mathrm{~s}, 2 \mathrm{H})$.

1,4-diethynylbenzene. This compound was prepared by a modified literature procedure. ${ }^{2}$ 1,4-diiodobenzene (18.0 g, $54.6 \mathrm{mmol}), \mathrm{Pd}\left(\mathrm{PPh}_{3}\right)_{2} \mathrm{Cl}_{2}(0.4 \mathrm{~g}, 0.57 \mathrm{mmol})$ and $\mathrm{CuI}(0.1 \mathrm{~g}, 0.525$ mmol) were dissolved in a mixture of THF and diisopropylamine (200 mL, 8:2) which has been 
previously deoxygenated by 30 min of bubbling with $\mathrm{N}_{2}$. This solution was cooled with an ice bath whereupon trimethylsilylacetylene $(20 \mathrm{~mL}, 13.9 \mathrm{~g}, 0.142 \mathrm{mmol})$ was added dropwise with stirring and under positive pressure of nitrogen. After a small volume $(<5 \mathrm{~mL})$ was added, an endothermic reaction was observed with formation of a thick precipitate of white powder. After the addition was complete, the reaction was allowed to warm to room temperature and it was stirred an additional twenty-four hours. After this time, the reaction mixture was a dark color. The solvents were removed by rotory evaporation and the remaining black solid was washed several times with water and a water-methanol (40:60) mixture. The solid was then dissolved in hot hexane, decolorized with active charcoal, and passed through a short column of alumina. The resulting white solid was recrystallized from acetone/water to afford 1,4-bis(trimethylsilylethynyl)benzene as shiny white crystalline flakes. The 1,4-bis(trimethylsilylethynyl)benzene crystals were dissolved in a mixture of THF and methanol (80:20). To the resulting solution was added a solution of KF (10.0 g) and a spatula-tip of tetrabutylammonium bromide in water $(80 \mathrm{~mL})$. The resulting suspension was vigorously stirred at room temperature under $\mathrm{N}_{2}$ for 12 hours, and then diluted with water until the product precipitated as a fine white powder. The solid was collected by vacuum filtration, washed with water and recrystallized from methanol/water to afford 1,4-diethynylbenzene as a white solid, yield $5.6 \mathrm{~g}(81 \%)$.

4,4'-diethynylbiphenyl. This compound was prepared by the same procedure as described above for 1,4-diethynylbenzene, except that 4,4'-diiodobiphenyl was used in place of 1,4diethynylbenzene. The product was obtained as a white solid, yield for the two steps $75 \%$.

Generation of the Ph- $\mathrm{T}_{3}$ Radical Cation by Photoinduced Electron Transfer/Laser Flash Photolysis

The radical cation of $\mathrm{Ph}-\mathrm{T}_{3}$ was generated by photoinduced electron transfer from the triplet excited state $\left({ }^{3} \mathrm{Ph}-\mathrm{T}_{3}{ }^{*}\right)$ to $\mathrm{N}, \mathrm{N}^{\prime}$-dimethylviologen $\left(\mathrm{MV}^{2+}\right)$. To a $15 \mathrm{mM}$ solution of $\mathrm{MV}^{2+}$ in THF/acetonitrile (2:1) $\mathrm{Ph}-\mathrm{T}_{3}$ was added until the absorbance at $355 \mathrm{~nm}$ was 0.7 . The solution 
was subjected to $10 \mathrm{~mJ}, 355 \mathrm{~nm}$ laser pulses to generate the cation radical via photoinduced electron transfer, i.e.,

$$
\begin{aligned}
& \mathrm{Ph}-\mathrm{T}_{3}+\mathrm{h} v(355 \mathrm{~nm}) \rightarrow{ }^{3} \mathrm{Ph}-\mathrm{T}_{3}{ }^{*} \\
& { }^{3} \mathrm{Ph}_{-} \mathrm{T}_{3}{ }^{*} \mathrm{MV}^{2+} \rightarrow \mathrm{Ph}^{-} \mathrm{T}_{3}^{+}+\mathrm{MV}^{+}
\end{aligned}
$$

The difference absorption spectrum of the cation radical shown in Figure S-2 was measured using a laser flash photolysis system that has been described previously. ${ }^{3}$

\section{References}

(1) Zhou, Q.; Swager, T. M. J. Am. Chem. Soc. 1995, 117, 12593-12602.

(2) Takahashi, S.; Kuroyama, Y.; Sonogashira, K.; Hagihara, N. Synthesis 1980, 627-630.

(3) Wang, Y. S.; Schanze, K. S. Chem. Phys. 1993, 176, 305-319. 
Table S-1. Photophysical Data for PPE Polymers in THF Solution

\begin{tabular}{|c|c|c|c|c|c|c|}
\hline \multirow[b]{2}{*}{ polymer } & \multirow[b]{2}{*}{$\lambda_{\mathbf{m m}}^{\mathrm{nmaxs}} /$} & \multirow[b]{2}{*}{$\mathbf{M}_{\mathbf{m a x}}^{-1}{ }^{-1}$} & \multirow[b]{2}{*}{$\underset{\mathbf{n m}}{\lambda_{\max }^{\mathrm{flr}}} /$} & \multirow[b]{2}{*}{$\phi_{\mathrm{em}}^{\mathrm{flr}}$} & \multirow{2}{*}{$\frac{450 \mathrm{~nm}}{\tau_{\mathrm{fl}} / \mathbf{n s}(\alpha)^{\mathrm{a}}}$} & \multirow{2}{*}{$\frac{550 \mathrm{~nm}}{\tau_{\mathrm{fl}} / \mathrm{ns}(\alpha)^{\mathrm{a}}}$} \\
\hline & & & & & & \\
\hline $\mathrm{PPE}_{164}$ & 411 & $5.6 \times 10^{4}$ & 452 & 0.33 & $\begin{array}{l}0.5(0.97) \\
3.9(0.03)\end{array}$ & $\begin{array}{l}0.6(0.80) \\
2.5(0.20)\end{array}$ \\
\hline $\mathrm{T}_{3} \mathrm{PPE}_{13}$ & 414 & $6.5 \times 10^{4}$ & 453,496 & 0.44 & $\begin{array}{l}0.5(0.94) \\
3.4(0.06)\end{array}$ & $\begin{array}{l}0.6(0.89) \\
3.2(0.11)\end{array}$ \\
\hline
\end{tabular}

${ }^{a}$ Fluorescence decay lifetimes from biexponential fits. $\tau$ and $\alpha$ values are, respectively, the lifetimes and normalized amplitudes of the individual decay components. 
Figure S-1 Absorbance (1000 nm) as a function of time after an electron pulse for solutions of $\mathrm{PPE}_{164}$ (PPE) and varied concentrations of terthiophene $\left(\mathrm{T}_{3}\right)$ in 1,2-dichloroethane $+1.6 \mathrm{M}$ toluene. The absorbance at this wavelength is almost entirely due to $\mathrm{PPE}^{+}{ }^{\bullet}$. Both the rate of charge transfer and approach to equilibrium are evident, along with the complication that an additional species is formed at long times, especially at the highest concentration, $216 \mu \mathrm{M} \mathrm{T}_{3}$. At short times $(<0.5 \mu \mathrm{s})$ strong absorption of the toluene dimer cation is evident, most notably in the trace containing only $0.39 \mathrm{mM} \mathrm{T}_{3}$.

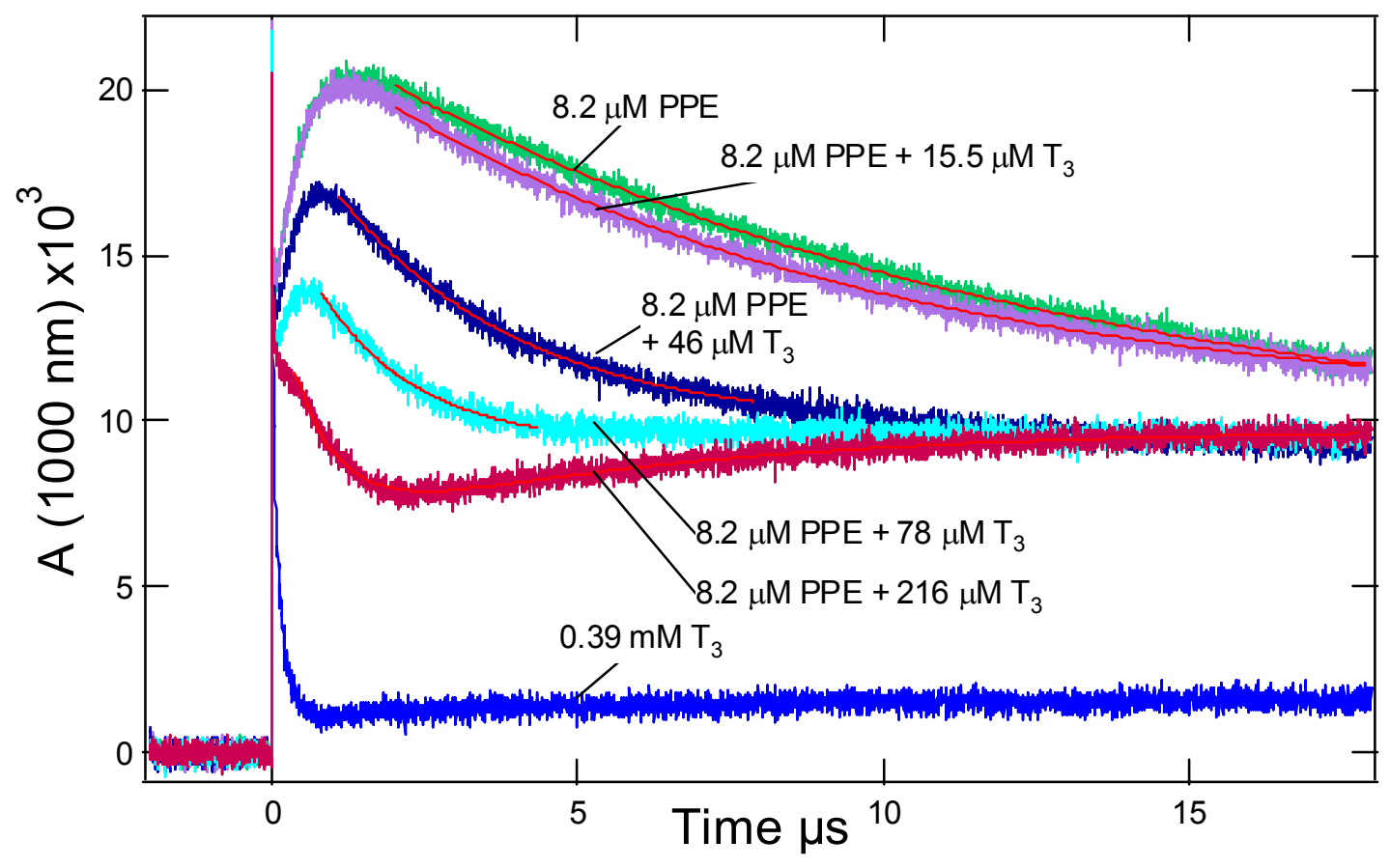


Figure S-2 Transient absorption difference spectrum of $\mathrm{Ph}-\mathrm{T}_{3}{ }^{+}$. produced by photoinduced electron transfer using N,N'-dimethylviologen as an acceptor. The spectrum was recorded 400 $\mathrm{ns}$ after the $355 \mathrm{~nm}$ laser excitation pulse. The cation radical features absorption maxima at $\approx$ 625 and $1040 \mathrm{~nm}$.

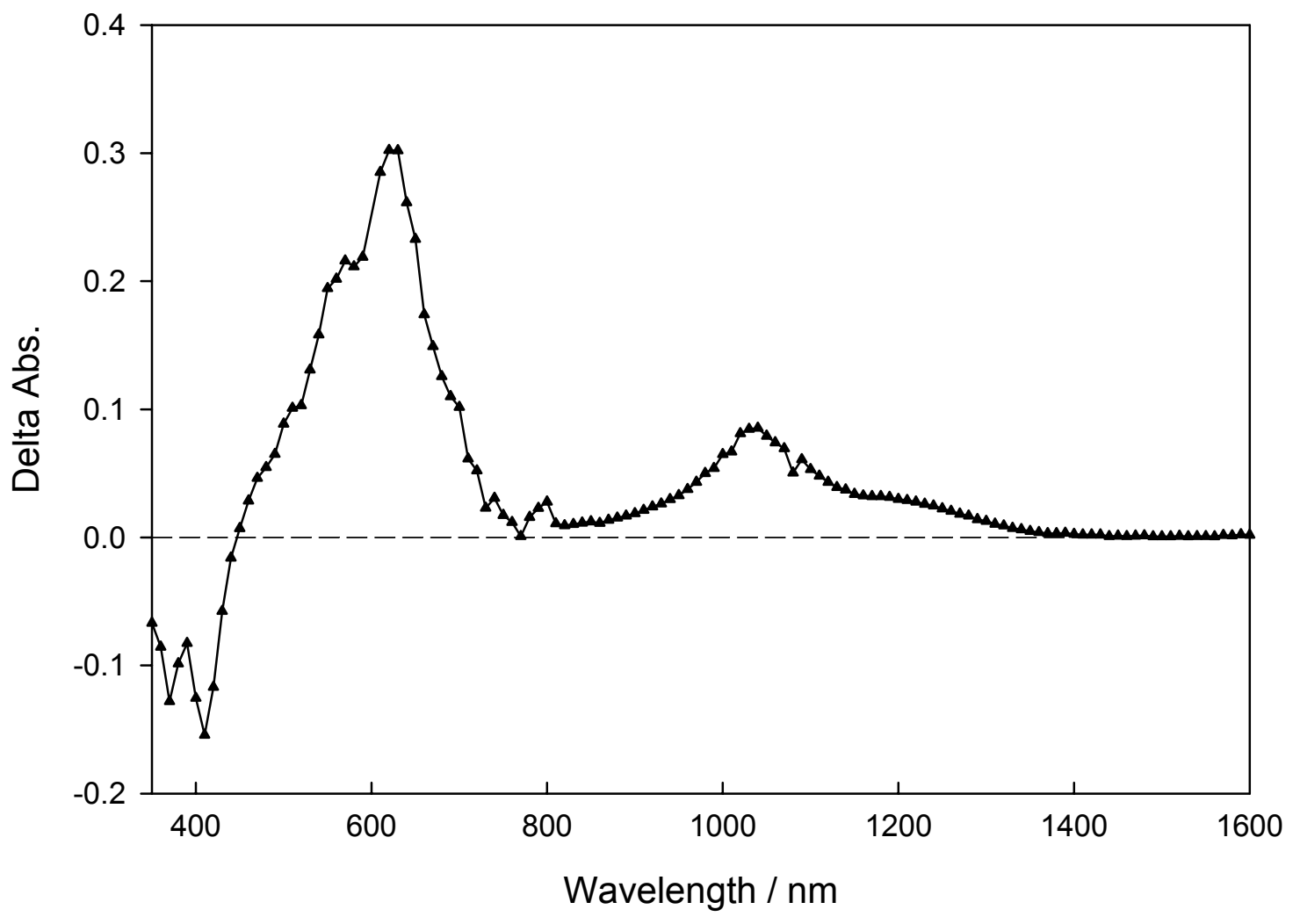


Figure S-3 Annotated $\mathrm{H}^{1}$ NMR Spectrum of $\mathrm{T}_{3} \mathrm{PPE}_{13}$

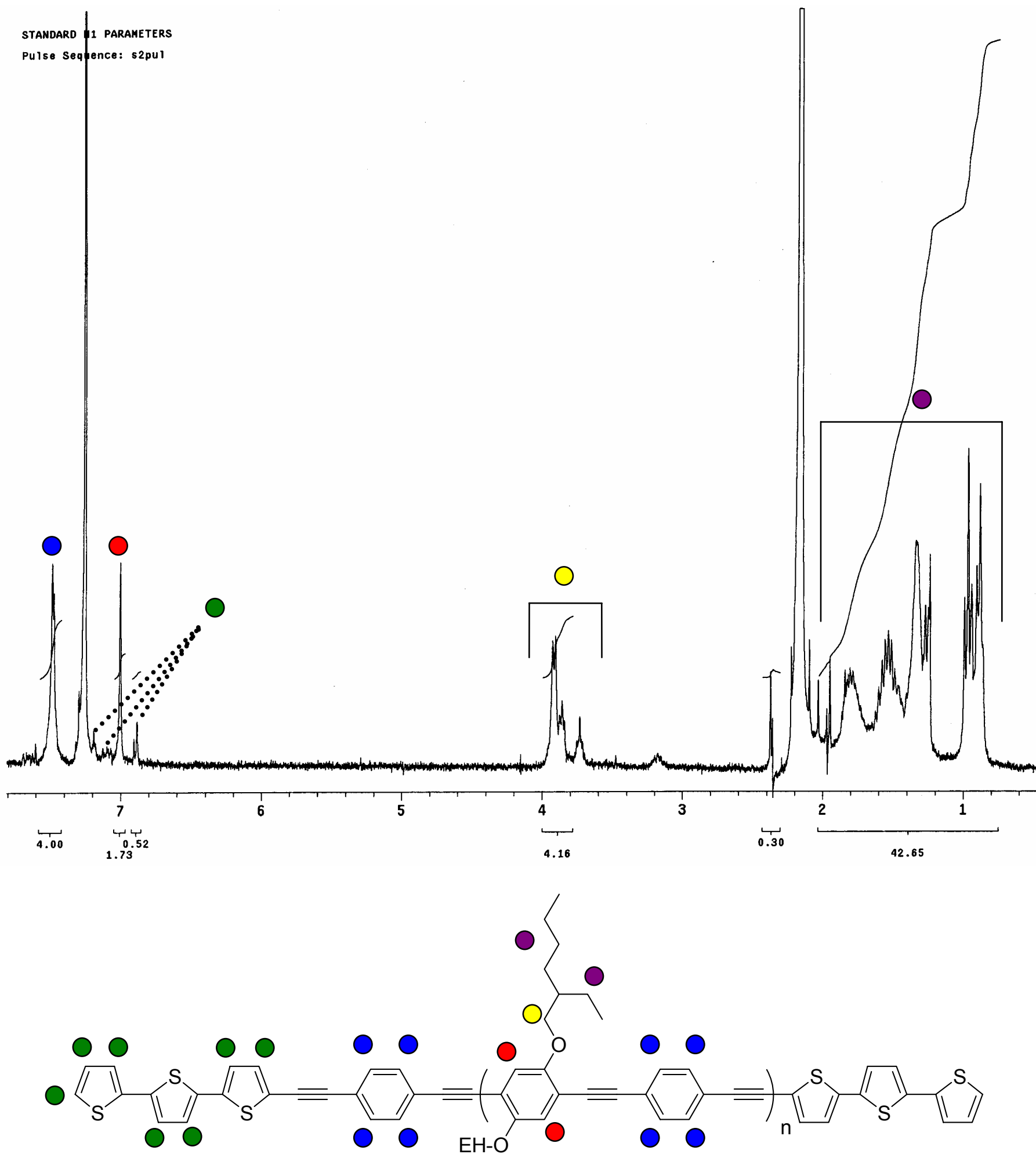

